\title{
Recombinant vascular endothelial growth factor 121 decreases vascular cell adhesion molecule- 1 in murine pre-eclampsia model placenta
}

\author{
Sri Sulistyowati*, John Arianto Sondakh*, Eric Edwin Yuliantara*, \\ Supriyadi Hari Respati*, and Soetrisno*
}

\begin{tabular}{l}
\hline \\
*Department of Obstetrics and \\
Gynecology, \\
Faculty of Medicine, \\
Universitas Sebelas Maret/ \\
RSUD Dr. Moewardi, Surakarta \\
Correspondence: \\
Dr. dr. Sri Sulistyowati, Sp.OG(K) \\
Department of Obstetrics and \\
Gynecology \\
RSUD Dr. Moewardi \\
J1. Kol. Sutarto 132 Surakarta \\
Phone: +62271 665145 \\
Email: elis_spog@yahoo.co.id
\end{tabular}

Univ Med 2016;35:192-8

DOI: 10.18051/UnivMed.2016.v35.192-198 pISSN: 1907-3062 / eISSN: 2407-2230

This open access article is distributed under a Creative Commons Attribution-Non Commercial-Share Alike 4.0 International License

\section{ABSTRACT}

\section{BACKGROUND}

Preeclampsia is one of the major contributors to maternal and fetal morbidity and mortality. Imbalance of soluble Fms-like tyrosine kinase (sFlt-1) as anti-angiogenic factor and vascular endothelial growth factor (VEGF) as pro-angiogenic factor plays a role in the pathogenesis of preeclampsia. Endothelial dysfunction in preeclampsia causes vascular cell adhesion molecule-1 (VCAM-1) to be expressed on its surface. This study aims to evaluate the effect of recombinant VEGF-121 on VCAM-1 expression in the placenta of a murine preeclampsia model.

\section{METHODS}

An experimental analytical study conducted from February until March 2016 in the Biomedical Laboratory, Faculty of Veterinary Medicine, Airlangga University. The study sample consisted of 30 pregnant mice, divided into three groups, i.e. 10 normal pregnant mice, 10 mice with preeclampsia model and 10 mice with preeclampsia model and recombinant VEGF-121 therapy. All animals were subjected to immunohistochemical examination of VCAM-1 expression in their placentas. The results were assessed semiquantitatively according to a modified Remmele method. Data analysis was done using one-way ANOVA and Tukey's multiple comparisons method.

\section{RESULTS}

Mean VCAM-1 expression in normal $(0.97 \pm 0.54 \%)$ murine placentas, compared with placentas $(2.94 \pm 0.96 \%)$ of murine preeclampsia models $(\mathrm{p}=0.000)$, while mean VCAM-1 expression in placentas of murine preeclampsia models with VEGF intervention was $2.14 \pm 0.68 \%$ $(\mathrm{p}=0.030)$.

\section{CONCLUSION}

Recombinant VEGF-121 can reduce VCAM-1 expression in placentas of murine preeclampsia models. The present study has shown the potential benefits of VEGF therapy, justifying serious consideration of this therapeutic approach for use in women with preeclampsia.

Keywords: Recombinant VEGF-121, VCAM-1, preeclampsia, pregnant murine 


\section{INTRODUCTION}

Preeclampsia is pregnancy that is associated with hypertension occurring after 20 weeks of gestation. Preeclampsia is still the main contributor to maternal and fetal morbidity and mortality. ${ }^{(1)}$ The incidence of preeclampsia is 2$10 \%$ of all pregnancies in the world and according to the WHO is 7-fold greater in developing than in developed countries. ${ }^{(2)}$ Preeclampsia is also associated with $10 \%$ of perinatal and neonatal causes of death. ${ }^{(3)}$ Between $30-40 \%$ of preeclampsia cases in Indonesia result in the death of the pregnant mothers and $30-50 \%$ cause perinatal deaths.

In RSUD Dr. Moewardi, Surakarta, the mortality rate among pregnant mothers in 2012 caused by preeclampsia was 19 out of 30 pregnant mothers and in 201312 out of 21 pregnant mothers. ${ }^{(4)}$

Preeclampsia can cause complications in the mother, i.e. acute kidney disease, liver failure, antepartum hemorrhage, postpartum hemorrhage, eclampsia and maternal death. ${ }^{(5)}$ Complications in the fetus that may be caused by preeclampsia are among others: intrauterine fetal death (IUFD), intrauterine growth restriction (IUGR), fetal distress, and also increased risk of respiratory distress and low birth weight associated with prematurity. ${ }^{(6)}$ Preeclampsia is described as a syndrome specific to pregnancy that can influence all organ systems. To date no effective preventive treatment of preeclampsia is available. Termination of pregnancy or delivery is considered the best measure, particularly in cases of preeclampsia with complications. ${ }^{(7)}$

Preeclampsia presumably occurs in two stages. The first stage is asymptomatic and is characterized by abnormal placental development in the first trimester, particularly in angiogenesis, causing placental insufficiency and release of placental material into the maternal circulation. In the endothelialization process there occur cytotrophoblast abnormalities and inadequate invasion of the spiral arteries in the myometrium. Poor placentation results in placental ischemia and hypoxia. Release of placental material triggers the clinical picture of the second stage, i.e. the symptomatic stage. In this stage there occurs the development of signs of hypertension, renal abnormalities and proteinuria, and damage in other end organs, leading to histological, functional, and metabolic placental abnormalities, that are thought to play a major role in the pathophysiology of preeclampsia. ${ }^{(8)}$

In the pathogenesis of preeclampsia there is presumably an imbalance between the proangiogenic placental growth factor (PIGF) and vascular endothelial growth factor (VEGF) on the one hand and the angiogenesis inhibitors (antiangiogenic factors) sFlt-1 and soluble endoglin (sEng). The balance between PIGF and VEGF as pro-angiogenic factors and sFlt-1 and sEng as anti-angiogenic factors is important in influencing the processes of angiogenesis, vasculogenesis and placental development during pregnancy. ${ }^{(9,10)}$

One of the facts that constitute strong evidence for the role of an imbalance between proand anti-angiogenic factors in preeclampsia is the increase in soluble fms-like tyrosine kinase-1 (sFlt1). The aforementioned imbalance can be detected before the clinical diagnosis of preeclampsia. Currently measurement of serum sFlt-1 levels and the ratio of sFlt-1 to PIGF may be used as predictors of preeclampsia. An sFlt-1/PlGF ratio of $<38$ can be used as a strong predictor of preeclampsia in women who are clinically at risk. ${ }^{(11)}$ Placental ischemia in experimental animals causes reduced uterine perfusion pressure (RUPP) that produces increased levels of sFlt-1 and decreased levels of free VEGF in the circulation. ${ }^{(12)}$ In endothelial dysfunction, on the endothelial surface adhesion molecules are expressed, such as vascular cell adhesion molecule-1 (VCAM-1) and intercellular cell adhesion molecule-1 (ICAM1). In the supernatants of endothelial cell cultures that have been incubated with the serum of patients with preeclampsia, increases are found in soluble VCAM-1, but not in other adhesion molecules such as ICAM-1 and E-selectin. Therefore VCAM-1 presumably plays a role in preeclampsia. ${ }^{(13,14)}$ 
Recombinant VEGF-121 is an exogenous VEGF that plays a role in vasculogenesis and angiogenesis, since there are VEGF receptors (VEGFR-1) in the endothelial wall. Administration of recombinant VEGF for the treatment of preeclampsia may result in reduced sFlt-1 levels in the blood of experimental animals, clinically reduced blood pressure, histopathological improvement of endothelial function, and reduction of placental hypoxia. ${ }^{(15,16)}$ Recombinant VEGF therapy can neutralize the increased sFlt-1 in preeclampsia, thus reducing sFlt-1 concentration and resulting in a return to normal angiogenesis. ${ }^{(3)}$ The VEGF-121 therapy in a murine model of preeclampsia has the effects of reducing blood pressure, improving albumin and creatinine, placental histology, and glomerular endotheliosis. ${ }^{(15)}$

Thus far there have not been many studies on recombinant VEGF-121 therapy in relation to VCAM-1 expression as marker of endothelial dysfunction in preeclampsia. The present study aimed to evaluate the influence of recombinant VEGF-121 administration on VCAM-1 expression in the placenta of a murine model of preeclampsia.

\section{METHODS}

\section{Design of the study}

This was an experimental analytical study, conducted from February until March 2016 in the Experimental Animal House, Biomedical Laboratory, Faculty of Veterinary Medicine, Airlangga University.

\section{Animal model}

The experimental animal study used murine placentas that meeting the inclusion criteria, i.e. originating from female Swiss mice (Mus musculus) obtained from center Veterinaria Farma Center, Surabaya. The mice were 3 months old, healthy, and weighing 20 to 25 grams. The sample size based on the replication formula of Steel et al. ${ }^{(17)}$ was 30 mice that were divided into 3 groups, i.e. group 1 (K1) comprising normal pregnant mice, group 2 (K2) comprising mouse preeclampsia models and group 3 (K3) comprising mouse preeclampsia models on recombinant VEGF-121 therapy. On day 16 of murine gestation, all animals from the three groups underwent an operation in which their placentas were removed. The reason for collecting the placentas on day 16 was the assumption that this period was comparable to the second trimester of pregnant humans, in which the manifestations of preeclampsia are already present.

Impregnation of the female mice was performed by estrus synchronization, in which female 3-month old adult mice weighing 20 to 25 grams were injected with $5 \mathrm{IU}$ of pregnant mare serum gonadotropin (PMSG), and 48 hours later injected with 5 IU human chorionic gonadotropin (hCG). The female mice that were already in synchronized estrus were mated with 7-months old male mice weighing \pm 60 grams. Seventeen hours after mating the female mice can be diagnosed as pregnant if there is a copulatory plug filling their vagina from cervix to vulva.

On day 1 of pregnancy, the whole sample was randomly divided into three groups, i.e. a group of 10 normal pregnant mice (K1) kept without intervention and 2 groups, each comprising 10 pregnant mouse as models of preeclampsia (K2 and K3). The mice were converted into a preeclampsia model by the intravenous administration on days 1 to 4 of anti Qa-2 antibody at a dose of $10 \mathrm{ng}$. On days 12 to 15 of pregnancy, the mice in group $\mathrm{K} 3$ received a single dose of recombinant VEGF-121 (125 mg/ $\mathrm{kg}$ body weight). On day 16 of pregnancy, the mice from all three groups were terminated by euthanasia using ketamine and subsequently underwent necropsy. After the abdominal cavity of each animal was opened, the placenta was removed and placed into a pot containing $10 \%$ neutral buffered formalin. The placenta was then subjected to immunohistochemical examination. The reagent kits used were anti-Qa2 antibody (5K44), Xeno-free ${ }^{\mathrm{TM}}$ recombinant mouse VEGF$121125 \mathrm{mg} / \mathrm{kg}$ body weight, pregnant mare serum gonadotropin (PMSG) 600 pg, Chorulon human chorionic gonadotropin (hCG) $1500 \mathrm{IU}$ and Bioss VCAM. 


\section{Immunohistochemistry}

Preparations were obtained from each of the surgically removed murine placentas, made into paraffin blocks and stained with hematoxylineosin (HE). Histological sections were prepared by fixing the placentas in $10 \%$ neutral buffered formalin, then cutting them up and placing them in plastic containers. The specimens were further dehydrated in graded alcohols of $70 \%, 80 \%, 90 \%$, absolute alcohol I, absolute II, each immersion lasting 2 hours. The specimens were then cleared in xylol, molded into paraffin blocks and stored in the refrigerator. The aforementioned blocks were then cut into 5-6 ì m sections in a microtome. The sections were floated in warm water at a temperature of $60^{\circ} \mathrm{C}$ to stretch the sections to prevent folds in the tissues. The preparation were then lifted out and placed on a glass slide for staining with hematoxylin and eosin (HE). Subsequently the sections were examined under a Nikon eclipse CY1 light microscope at 1000x magnification. Immunohistochemical examination was performed to evaluate VCAM-1 expression, calculated as the percentage of positive cells per field of view.

\section{Data analysis}

Data were analyzed semiquantitatively according to a modification of the Remmele method, where the Remmele scale index (immunoreactive score, IRS), ${ }^{(18)}$ is the product of the percentage of immunoreactive cells and the color intensity of these cells. The analytical technique used in this study was the one-way ANOVA statistical test. In case of a significant difference, the analysis was continued with the post hoc Tukey test, at a significance level of 5\% $(\mathrm{p}<0.05)$.
Table 2. Results of post-hoc analysis using

Tukey's procedure

\begin{tabular}{lcc}
\hline Grouping & Meandifference & p \\
\hline K1 K2 & -1.87 & 0.000 \\
K3 & -1.04 & 0.001 \\
K2 K3 & 0.76 & 0.035 \\
\hline
\end{tabular}

$\mathrm{K} 1=\mathrm{VCAM}-1$ in normal pregnant murine placentas; $\mathrm{K} 2=$ murine preeclampsia model placentas; $\mathrm{K} 3=$ murine preeclampsia model placentas treated with recombinant VEGF-121

\section{Ethical clearance}

Ethical clearance was obtained from the Research Ethics Commission, Faculty of Veterinary Medicine, Airlangga University, under No. 419-TO, dated 18 March 2015.

\section{RESULTS}

In Table $1 \mathrm{~K} 1$ has a mean VCAM-1 score of $0.97 \pm 0.54 \%$ per field of view, group K2 a mean score of $2.94 \pm 0.96 \%$ per field of view, while group K3 has a mean score of $2.14 \pm 0.68 \%$ per field of view $(\mathrm{p}=0.000)$. The mean VCAM-1 score between the three groups differed significantly.

Mean VCAM differed significantly between group $\mathrm{K} 1$ and group $\mathrm{K} 2(\mathrm{p}=0.00)$, group $\mathrm{K} 1$ differed significantly from group $\mathrm{K} 3(\mathrm{p}=0.001)$ and group $\mathrm{K} 2$ differed significantly from group $\mathrm{K} 3$ ( $\mathrm{p}=0.035$ ) (Table 2). From these study results it may be concluded that recombinant VEGF-121 administration reduced VCAM-1 expression in the preeclampsia model placentas.

In Figure 1 it is apparent that there was no dominant chromogen pattern as a marker of VCAM-1 expression in the endothelium of normal pregnant murine placentas (K1), whereas in murine preeclampsia model placentas (K2) and murine preeclampsia model placentas treated with

Table 1. Mean VCAM-1 in normal pregnant murine placentas (K1), murine preeclampsia model placentas (K2) and murine preeclampsia model placentas treated with recombinant VEGF-121 (K3)

\begin{tabular}{lcccc}
\hline \multicolumn{1}{c}{ Variable } & $\begin{array}{c}\text { K1 } \\
(\mathbf{n}=\mathbf{1 0})\end{array}$ & $\begin{array}{c}\text { K2 } \\
(\mathbf{n}=\mathbf{1 0})\end{array}$ & $\begin{array}{c}\text { K3 } \\
(\mathbf{n = 1 0})\end{array}$ & $\mathbf{p}$ \\
\hline $\begin{array}{l}\text { VCAM-1 } \\
\text { (perc entage of cells per field of view) }\end{array}$ & $0.97 \pm 0.54$ & $2.94 \pm 0.96$ & $2.14 \pm 0.68$ & $0.000 *$ \\
\hline
\end{tabular}



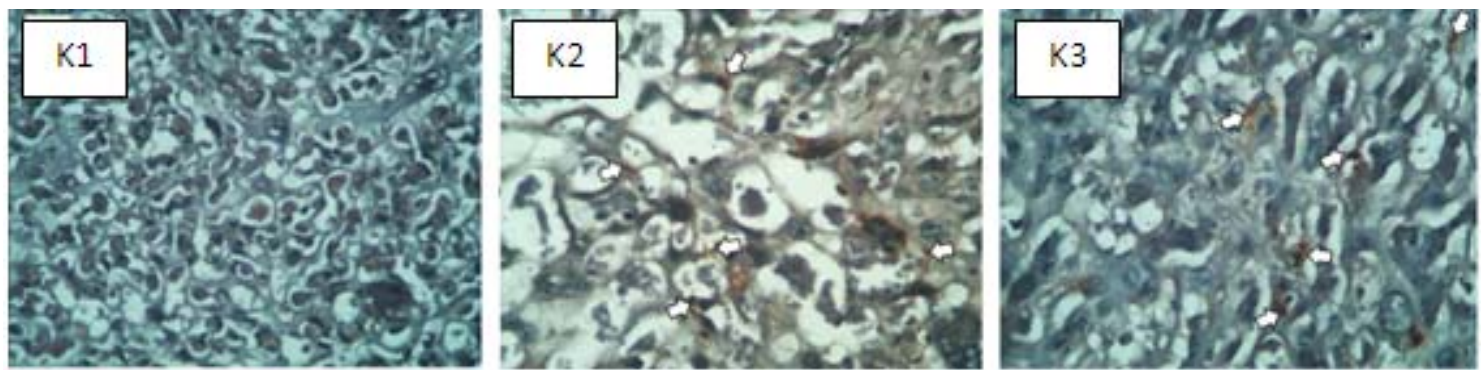

Figure 1. VCAM-1 expression in normal pregnant murine placentas (K1), murine preeclampsia model placentas (K2) and murine preeclampsia model placentas treated with recombinant VEGF-121 (K3)

recombinant VEGF-121 (K3) may been seen chromogen patterns (indicated by white arrows) showing VCAM-1 expression in the endothelium of murine placentas. The chromogen pattern in K-2 (endothelium of pregnant murine preeclampsia model placentas) was more dominant than in K-3 (endothelium of pregnant murine preeclampsia model placentas treated with recombinant VEGF-121), the latter showing lower VCAM-1 expression.

\section{DISCUSSION}

In this study mean VCAM-1 expression in the group of normal pregnant mice was significantly lower than in the preeclampsia model mice. This demonstrates that in preeclampsia there occurs endothelial dysfunction because of significantly increased VCAM-1 expression.

Endothelial dysfunction in preeclampsia is characterized by expression of adhesion molecules on the endothelial, i.e. VCAM-1 and ICAM-1. Increases in the concentrations of soluble VCAM1 are found in the supernatant of endothelial cell cultures that were incubated with the serum of patients with preeclampsia, but no increases in other adhesion molecules such as ICAM-1 and E-selectin. Therefore it is presumed that VCAM1 plays a role in preeclampsia. ${ }^{(13)}$ This study agrees with other studies that increased VCAM-1 indicates the possibility of altered endothelial activity and therefore of endothelial damage in preeclampsia. Increased VCAM-1 indicates activation of endothelial cells. ${ }^{(19)}$

Recombinant VEGF-121 has receptors called VEGFR-1 in the endothelial wall, which may also bind sFlt-1 more strongly. Recombinant VEGF-121 binds to VEGFR-1, thus triggering angiogenesis. Recombinant VEGF-121 therapy may also neutralize the effect of increased sFlt-1 in preeclampsia, in that binding of sFlt-1 to proangiogenic factors reduces circulating sFlt-1 and effects a return to normal angiogenesis. ${ }^{(3)}$

Administration of recombinant VEGF-121 for treatment of preeclampsia in experimental animals can lead to reduction in sFlt-1 concentrations in the circulation, clinical reduction in blood pressure, histopathological improvement in endothelial function and decreased placental hypoxia. ${ }^{(15,16)}$ The studies of Li et al, ${ }^{(15)}$ Bergmann et al, ${ }^{(20)}$ Gilbert et al, ${ }^{(21)}$ Mateus et al, ${ }^{(16)}$ and Woods et al, ${ }^{(7)}$ on administration of VEGF-121 in experimental animals show similar significant results, such as reduced systolic blood pressure and reduced renal damage. In the present study mean VCAM-1 expression in the group of murine preeclampsia models given recombinant VEGF121 was significantly lower than in the group of murine preeclampsia models alone. This shows that administration of or therapy with recombinant VEGF-121 significantly reduces VCAM-1 expression, signifying improvement of endothelial function in preeclampsia. Chronic infusion of VEGF-121 in rats with experimentally induced RUPP improves glomerular filtration rate and endothelial function, reduces high blood pressure and prevents the onset of hypertension in late gestation. ${ }^{(21)}$ In the study of Agarwal and Karumanchi ${ }^{(22)}$ on rats as preeclampsia models, administration of VEGF-121 shows improvement in glomerular filtration rate and endothelial function, and also reduces the blood pressure 
associated with placental ischemia and high sFlt1 expression.

In our study we did not investigate sFlt-1 expression, therefore treatment with recombinant VEGF-121 could not show improvement in the balance between the pro-angiogenic VEGF and the anti-angiogenic sFlt-1 in the form of a reduction of the endothelial dysfunction occurring in preeclampsia.

\section{CONCLUSIONS}

Recombinant VEGF-121 may reduce VCAM-1 expression in murine preeclampsia model placentas. Administration of recombinant VEGF-121 may be one alternative for developing preeclampsia therapies to reduce maternal and fetal morbidity and mortality.

\section{CONFLICT OF INTEREST}

The authors state that there is no conflict of interest in connection with the study, the authors, and/or the publication of this paper.

\section{ACKNOWLEDGMENTS}

We express our gratitude to all staff members of the Experimental Animal House, Biomedical Laboratory, Faculty of Veterinary Medicine, Airlangga University, who assisted in the preparation of the murine preeclampsia models.

\section{REFERENCES}

1. Osungbade KO, Ige OK. Public health perspectives of preeclampsia in developing countries: implication for health system strengthening. J Pregnancy 2011; Article ID 481095, 6 pages. http://dx.doi.org/10.1155/ 2011/481095.

2. Kooffreh ME, EkottM, Ekpoudom DO. The prevalence of pre-eclampsia among pregnant women in the University of Calabar Teaching Hospital, Calabar. Saudi J Health Sci 2014;3: 133-6.

3. Maynard SE, Karumanchi SA. Angiogenic factors and preeclampsia. Semin Nephrol 2011; 31:33-46.
4. Sulistyowati S, Soetrisno, Kartika NH. Ekspresi human leukocyte antigen-C di trofoblas dan natural killer cell di desidua pada preeklampsia berat. Jurnal Kedokteran Brawijaya 2016;29:5963.

5. Roberts CL, Ford JB, Algert CS, et al. Population-based trends in pregnancy hypertension and pre-eclampsia: an international comparative study. BMJ Open 2011;24:e000101. doi: 10.1136/bmjopen-2011-000101.

6. Aabidha PM, Cherian AG, Paul E, et al. Maternal and fetal outcome in pre-eclampsia in a secondary care hospital in South India. J Family Med Prim Care 2015;4:257-60.

7. Woods AK, Hoffmann DS, Weydert CJ, et al. Adenoviral delivery of VEGF 121 early in pregnancy prevents spontaneous development of pre-eclampsia in $\mathrm{BPH} / 5$ mice. Hypertension 2011;57:94-102.

8. Roberts JM, Hubel CA. The two stage model of preeclampsia: variation on the theme. Placenta 2009;30 Suppl A:S32-7.

9. Levine RJ, Lam C, Qian C, et al. Soluble endoglin and other circulating antiangiogenic factors in preeclampsia. N Engl J Med 2006;355: 992-1005.

10. Gu Y, Lewis DF, Wang Y. Placental productions and expressions of soluble fms-like tyrosine, soluble endoglin, and placental growth factor in normal and preeclamptic pregnancies. J Clin Endocrinol Metab 2008;93:260-6.

11. Zeisler H, Llurba E, Chantraine F, et al. Predictive value of the sFlt-1:PlGF ratio in women with suspected preeclampsia. N Engl J Med 2016;374:13-22. DOI: 10.1056/NEJMoa 1414838 .

12. Warrington JP, George EM, Palei AC, et al. Recent advances in the understanding of the pathophysiology of preeclampsia. Hypertension 2013;62:666-73.

13. Sulistyowati S, Abadi A, Hood J, et al. The influence of low HLA-G protein expression on HSP-70 and VCAM-1 profile in preeclampsia. Indonesian J Obstet Gynecol 2010;34:185-90.

14. Sulistyowati S, Abadi A, Wijiati M. Low class Ib (HLA-G/Qa2) MHC protein expression against HSP-70 and VCAM-1 profile on preeclampsia: an observation on experimental animal Mus musculus with endothelial dysfunction model. Indonesian J Obstet Gynecol 2010;34:103-6.

15. Li Z, Zhang Y, Ying Ma J, et al. Recombinant vascular endothelial growth factor 121 attenuates hypertension and improves kidney damage in a rat model of preeclampsia. Hypertension 2007;50:686-92. 
16. Mateus J, Bytautiene E, Lu F, et al. Endothelial growth factor therapy improves preeclampsialike manifestasions in a murine model induced by overexpression of sVEGFR-1. Am J Physiol Heart Circ Physiol 2011;301:H1781-7.

17. Steel RG, Torrie JH, Dickey DA. Principles and procedures of statistics: a biometrical approach. $3^{\text {rd }}$ ed. New York: McGraw-Hill Companies; 1997.

18. Halon A, Donizy P, Biecek P, et al. HER-2 expression in immunohistochemistry has no prognostic significance in gastric cancer patients. Sci World J 2012; Article ID 941259, 6 pages. DOI: $10.1100 / 2012 / 941259$.

19. Anwar AD, Achmad TH, Krisnadi SR, et al. Polimorfisme C1167T gen reseptor tipe II transforming growth factor-â, kadar soluble endoglin dan vascular adhesion molecule-1 pada preeklamsia. MKB 2010;42:115-22.
20. Bergmann A, Ahmad S, Cudmore M, et al. Reduction of circulating soluble Flt-1 alleviates preeclampsia-like symptoms in a mouse model. J Cell Mol Med 2001;14:1857-67.

21. Gilbert JS, Verzwyvelt J, Colson D, et al. Recombinant VEGF $_{121}$ infusion lowers blood pressure and improves renal function in rats with placental ischemia-induced hypertension. Hypertension 2010;55:380-5.

22. Agarwal I, Karumanchi SA. Preeclampsia and the anti-angiogenic state. Pregnancy Hypertens 2011;1:17-21. 